\title{
BREAST CANCER: REASONS FOR NOT PRACTICING BREAST SELF EXAMINATION AMONG WOMEN IN LUCKNOW, NORTH INDIA
}

\author{
SHIPRA $^{\mathrm{a} 1}$, REEMA KUMARI ${ }^{\mathrm{b}}$, V.K. SINGH ${ }^{\mathrm{c}}$ AND G.N. SINGH ${ }^{\mathrm{d}}$

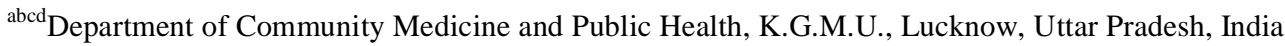

\begin{abstract}
Breast cancer is a major global health issue and was the most important reason behind morbidity and mortality among women. It remains a significant public health concern in both developed and developing countries. Works of literature have shown that in most of the developing countries breast cancer is detected in advanced stages when put up next with developed countries and thus has a poor outcome and high mortality rate. Less than one-fourth (22\%) of women in Lucknow had heard about breast self-examination. Few women (19\%) were practicing Breast self-examination (BSE) once in a while and therefore the common reason for not practicing Breast self-examination was unaware of the requirement and as they don't have any breast-related problems. Awareness of breast self-examination was poor collectively in rural and urban areas of Lucknow. Breast self-examination is had not been appropriately practiced but the curiosity to learn BSE is high.
\end{abstract}

KEYWORDS: Awareness, Breast Cancer, Knowledge, Screening, Breast Self-examination, Practices

According to World Health Organization (WHO), Breast cancer is the most commonly found cancer in women, and countless women are affected all over the world.. Cancer is a predominant explanation for death everywhere in the world accounting for 10 million deaths in 2020.The most common in 2020 (in terms of new cases of cancer) were breast (2.26 million cases), lung (2.21 million cases), colon and rectum (1.93 million cases),prostate (1.41 million cases), skin (non-melanoma) (1.20 million cases), and stomach (1.09 million cases). (WHO, 2020)

According to Globocan, Breast carcinoma is one-fourth $(25 \%)$ of all cancer and $(15 \%)$ of all cancerrelated deaths among women. Aging populations globally and risk factors remain among the most common factors leading to this increase in cases (Globocan 2020 statistics)

Now for the first time, female breast carcinoma has now ahead of lung cancer due to high prevalence in low- and middle-income countries (LMICs). The most common age group of Breast cancer in developed countries is above the age of 50 years, as compared to India, where it occurs in a younger age group. Cancers within the young (15-34 years) tend to be more aggressive which may be a reason behind concern as this denotes the requirement for awareness programs of younger women's early as 18 years, to implement early practices of breast self-examination (BSE) into their lifestyle. Breast cancer in developing counties is half of total breast cancer cases in the world and around (60\%) of breast cancer death occurs in developing countries. The incidence in developing countries is low but mortality is high due to late presentation, due to lack of awareness of screening methods and practices related to it.(WHO)

Detection of Breast cancer in the early stage plays a very important role in the prevention of breast cancer. The 5 year survival rate has reached approximately $(85 \%)$ with early detection, whereas later detection has decreased the survival rate to (56\%). (ICMR)

For early detection, there are screening methods like BSE, Clinical breast examination (CBE), and Mammography but the use of these methods is limited due to lack of infrastructure, trained manpower, and limited knowledge. So, BSE is preferred in low-income countries as it is simple, easy, and cost-effective for early detection of the lump (Malvia et al., 2017)

American cancer society (ACS) recommends BSE practice and education for women ( $\geq 20$ years) but it does not mention BSE as a tool to increase survival of breast cancer. (ACS Guidelines)

In the study, Gangane et al., (2015) stated that Breast self-examination is hardly practiced in developing countries like India, though the curiosity to learn is high.

According to Breast Health Global Initiative guidelines for low and middle-income countries, BSE

${ }^{1}$ Corresponding author 
remains the tool for decreasing mortality with Breast cancer in low and middle-income countries, in actual practice its application is low.

Although breast cancer is the most prevalent cancer in India, there is no organized national breast cancer screening program. Local studies on the burden of breast cancer are essential to developing effective context-specific strategies for an early detection breast cancer program. This study assessed practices related to self-breast examination and reasons for not practicing Breast-self-examination among women in Lucknow, North India.

\section{MATERIALS AND METHODS}

In the present study reasons for not practicing BSE among women in Lucknow, North India was assessed. The study is also geared towards suggesting measures for improving the knowledge and practices associated with Breast carcinoma among women in Lucknow if required.

An extensive search of literature published was conducted in the electronic databases of PubMed and Google Scholar. All English language studies including information on knowledge, awareness and practice of breast carcinoma and its screening were reviewed.

The present study was conducted on 400 women, aged $\geq 20$ years, selected randomly from Lucknow District (U.P) from 2 rural and 2 urban areas of Lucknow. A pre-tested structured questionnaire was accustomed to collect the knowledge from the respondents with an aim to satisfy the objectives of the proposed study. In-depth interviews were conducted with participants to extract their knowledge and beliefs of early detection methods and screening practices of breast self-examination. The age group, marital status, education level, occupation, and socioeconomic status of all the respondents were noted and their beliefs of screening practices including BSE were studied and reasons for not practicing BSE. For calculating socioeconomic status, modified Prasad scale was used. Responses to numerous queries were encoded in numbers and their statistical distribution was calculated using SPSS software. Chi-square was applied to check the importance level of differences between responses of various socio demographic classes of respondent

\section{RESULTS}

The present study was done to assess the reasons for not practicing self-breast examination among women in Lucknow, North India. The study also aims to suggest measures for improving the practices related to self-breast examination. Present study results can be classified into the following sub-groups: Socio-demographic characteristics of the respondents, practices of BSE, reasons for not practicing $\mathrm{BSE}$ and association of BSE with socio-demographic characteristics.

The majority of the respondents belong to the age range $20-30$ years $(73.8 \%)$ followed by the age group $31-40 \mathrm{yr}(20.3 \%)$. The majority of women $(91.3 \%)$ were married and were Hindu (77.1\%). Only (33.8\%) belong to the general category, most of the participants were from OBC category while most of the subjects were housewife/unemployed category $(84.8 \%)$. There were more respondents from class IV and class V SES $(30.8 \%$ and 31.5) (Table 1).

For those who know about the screening methods to detect early Breast cancer, only (19\%) were practicing it but the majority of the $(81 \%)$ women were not practicing. Almost half of the women (51.2\%) were practicing it occasionally and $(7.3 \%)$ did it rarely. 20-30 yr was the major age at which respondent started doing a Breast self-examination (51.2\%) while major examination technique applied during BSE by the respondent was inspection and palpation of the breast (36.6\%). (Table 2)

The majority of women who had knowledge but were not practicing BSE were $(81 \%)$ and the most common reason cited by them was unaware of need which was $55.5 \%$ followed by an absence of Breast related symptoms $(12.3 \%)$. (Table 3 ) 
SHIPRA ET AL.: BREAST CANCER: REASONS FOR NOT PRACTICING BREAST SELF EXAMINATION AMONG....

Table 1: Distribution of participants according to Socio-demographic characteristics $(n=400)$

\begin{tabular}{|c|c|c|}
\hline \multirow{2}{*}{ Socio demographic characteristics } & Frequency & Percentage \\
\hline & (n) & $(\%)$ \\
\hline \multicolumn{3}{|l|}{ Age( in completed years) } \\
\hline $20-30$ & 295 & 73.8 \\
\hline $31-40$ & 81 & 20.3 \\
\hline $41-50$ & 20 & 5.0 \\
\hline $50-60$ & 4 & 1.0 \\
\hline Mean age \pm SD & \multicolumn{2}{|c|}{$28.32 \pm 6.72 \mathrm{yr}$} \\
\hline \multicolumn{3}{|l|}{ Marital status } \\
\hline Single/Never married & 31 & 7.8 \\
\hline Married & 365 & 91.3 \\
\hline Widowed & 4 & 1.0 \\
\hline \multicolumn{3}{|l|}{ Religion } \\
\hline Hindu & 310 & 77.5 \\
\hline Muslim & 88 & 22.0 \\
\hline Sikh & 1 & .3 \\
\hline Christian & 1 & .3 \\
\hline \multicolumn{3}{|l|}{ Category } \\
\hline General & 135 & 33.8 \\
\hline $\mathrm{OBC}$ & 152 & 38.0 \\
\hline SC/ST & 113 & 28.3 \\
\hline \multicolumn{3}{|l|}{ Educational qualification } \\
\hline Illiterate & 78 & 19.5 \\
\hline Up to Primary school & 47 & 11.8 \\
\hline Middle school & 78 & 19.5 \\
\hline High-School & 74 & 18.5 \\
\hline Senior secondary school & 42 & 10.5 \\
\hline Graduate and above & 81 & 20.3 \\
\hline \multicolumn{3}{|l|}{ Occupation } \\
\hline Professional/technical/administrative/managerial, clerical, sales and services & 10 & 2.5 \\
\hline Skilled manual, semi-skilled, unskilled manual & 39 & 9.5 \\
\hline Agriculture & 2 & .5 \\
\hline Unemployed/Housewife & 339 & 84.8 \\
\hline \multicolumn{3}{|l|}{ Residence } \\
\hline Rural & 200 & 50.0 \\
\hline Urban & 200 & 50.0 \\
\hline \multicolumn{3}{|l|}{ Socioeconomic status } \\
\hline \multicolumn{3}{|l|}{ (modified B.G Prasad's classification) } \\
\hline Class I & 15 & 3.8 \\
\hline Class II & 67 & 16.8 \\
\hline Class III & 69 & 17.3 \\
\hline Class IV & 123 & 30.8 \\
\hline Class V & 126 & 31.5 \\
\hline
\end{tabular}


SHIPRA ET AL.: BREAST CANCER: REASONS FOR NOT PRACTICING BREAST SELF EXAMINATION AMONG....

Table 2: Distribution of the participants based on practices of breast self-examination (BSE)

\begin{tabular}{|c|c|c|}
\hline Variable & Frequency(n) & Percentage $(\%)$ \\
\hline \multicolumn{3}{|c|}{ Women's practicing Breast self-examination $(\mathrm{N}=50)$} \\
\hline yes & 9 & 19 \\
\hline no & 41 & 81 \\
\hline \multicolumn{3}{|c|}{ Frequency of practicing Breast self-examination $(\mathrm{N}=41)$} \\
\hline rarely & 3 & 7.3 \\
\hline monthly & 13 & 31.7 \\
\hline yearly & 4 & 9.8 \\
\hline occasionally & 21 & 51.2 \\
\hline \multicolumn{3}{|c|}{ Age at which respondent started doing breast self-examination $(\mathrm{N}=41)$} \\
\hline From puberty & 6 & 14.6 \\
\hline from 20 years & 6 & 14.6 \\
\hline $20-30 \mathrm{yrs}$ & 21 & 51.2 \\
\hline more than 35 yrs & 6 & 14.6 \\
\hline Never done & 2 & 4.9 \\
\hline \multicolumn{3}{|c|}{ Which examination technique applied during BSE by the respondent $(\mathrm{N}=41)$} \\
\hline Inspection of breast & 4 & 9.75 \\
\hline palpation of breast & 17 & 41.4 \\
\hline inspection and palpation of breast & 20 & 48.78 \\
\hline \multicolumn{3}{|c|}{ How the palpation of lump should be done during breast self-examination } \\
\hline Palpate with one finger & 2 & 4.9 \\
\hline palpate with palm & 9 & 22.0 \\
\hline Palpate with minimum of three fingers & 19 & 46.3 \\
\hline Hold breast in between fingers & 3 & 7.3 \\
\hline Don't know & 8 & 19.5 \\
\hline
\end{tabular}

Table 3: Distribution of the participants based on reasons for not breast self-examination (BSE)

\begin{tabular}{|c|c|c|}
\hline Variable & Frequency(n) & Percentage (\%) \\
\hline Women's practicing Breast self-examination (N=50) & 19 \\
\hline yes & 9 & 81 \\
\hline no & 41 & 55.5 \\
\hline \multicolumn{2}{|c|}{ Reason for not practicing BSE } \\
\hline Unaware of the need & 45 & 12.3 \\
\hline Don't have any breast-related problem & 10 & 9.8 \\
\hline Don't know the steps to perform BSE & 8 & 12.3 \\
\hline Don't think they should do & 10 & 2.4 \\
\hline Afraid of being detect Breast cancer with BSE & 2 & 1.23 \\
\hline Takes longer time & 1 & 6.17 \\
\hline
\end{tabular}




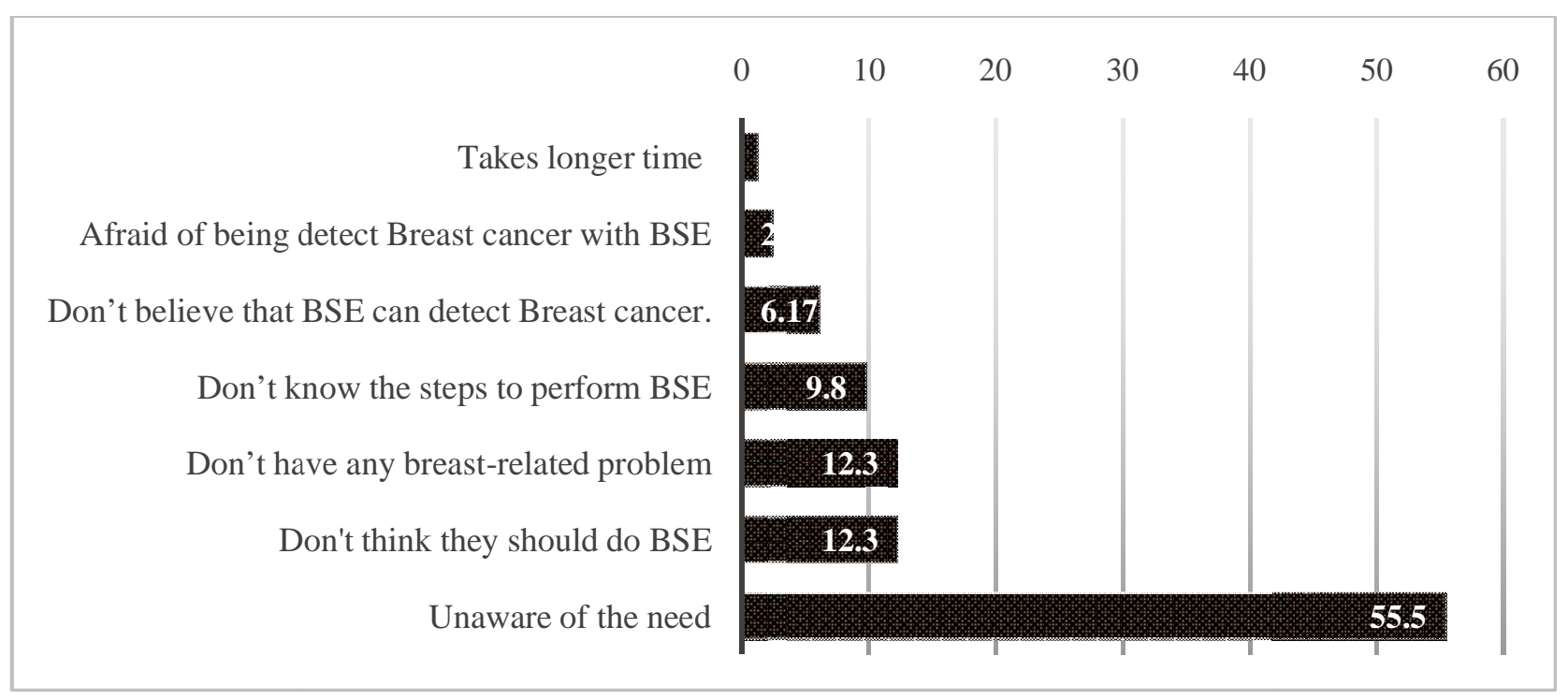

Figure 1: Graph showing reasons for not practicing breast self-examination (BSE)

\section{DISCUSSION}

The present study was thus conducted on women of Lucknow to assess reasons for not practicing Breast self Examination (BSE) among women in Lucknow district.

The majority $(73.8 \%)$ of the women were from age group 20-30yr of age which was similar to the study by (Paul et al., 2015) where women from 18-30yrs were $(66 \%)$. Overall mean age was $28.32 \pm 6.72 \mathrm{yr}$. which was found in agreement with the study by (Dahiya et al., 2018) where the mean age was $30.1 \pm 23.9$ yr it shows that both the study focused their study observations on women around 25 yrs (reproductive age). More women were Hindu $(77.5 \%)$ which was similar with the study by (Paul et al., 2015) where Hindu women were (92.6\%). The majority of the women in the present study were housewives $(85 \%)$ in contrast with the study conducted by (Dey et al., 2015) where the majority of women $(52 \%)$ were employed.

In the present study, less than one-fourth of women $(22.2 \%)$ had heard of BSE which was found in agreement with the study by (Somdatta and Baridalyne, 2013). The Knowledge and performance of BSE in the present study is $(22.2 \%$ and $18 \%)$ which was similar to the study in Varanasi by (Paul et al., 2015) where it was (16\% and $15.6 \%)$ respectively. These findings were in contrast with the study done (Fotedar et al., 2013) done on nursing students which were (97\% and 54\%).

For those who had knowledge about the Breast self Examination (BSE) to detect early Breast cancer, only $(19 \%)$ were practicing it but the majority of the $(81 \%)$ women were not practicing. Almost half of the women $(51.2 \%)$ were practicing it occasionally and $(7.3 \%)$ did it rarely on the contrary in one of the studies by (Dahiya et al., 2018) where Breast self-examination (BSE) was regularly practiced at least once a month by (41.4\%) of the participants.

In the present study, less than one-fourth of women $(18 \%)$ perform BSE while $(81 \%)$ were not performing BSE as the reason given by them were they feel it is unaware of the need (55.5\%) which was similar to the study by (Zavare, 2015) where $(57.3 \%$ ) believe that they feel it unnecessary which was in contrast with the study by (Dahiya et al., 2018). where almost onefourth of women $(20.7 \%)$ believe not to be needed. Nearly (12.3\%) half of the quarter women feel they don't have any Breast related problem which was in contrast with the study (Zavare, 2015) where $(64.7 \%)$ believe that they don't have any symptoms so they don't think they should perform (12.3\%) which was a slightly higher side than in the study by (Dahiya et al., 2018). which was (5\%). Another reason cited by them as they don't know how to do BSE $(9.8 \%)$ which was in contrast with the study (Dahiya et al., 2018) where a quarter of women (24.8\%) believe that they don't know how to perform BSE. In the present study, some women $(6.17 \%)$ don't believe that BSE can detect Breast cancer and few (2.4 $\%$ ) women were afraid of being detected of Breast cancer by BSE. Only (1.23\%) some women believe BSE steps take a longer time.

\section{CONCLUSION AND RECOMMENDATIONS}

The major reason for not practicing BSE was unaware of the necessity and they don't have Breastrelated problems as they responded. There wasn't much 
of the difference in BSE practices among rural and urban women of Lucknow. Breast self-examination is hardly practiced, though the willingness to learn is there. Health education in young women should be done more aggressively regarding various aspects starting from risk factors too numerous methods of screening, as younger age is more at risk to developing breast carcinoma in developing countries like India. BSE needs to get promoted mainly in the female having a family history of Breast cancer. We should always have major policy changes to increase future screening programs and health education schemes, which might have an overall positive impact on reducing the disease burden.

\section{ACKNOWLEDGMENT} study.

\section{REFERENCES}

American cancer society. https://www.cancer.org/cancer/ breast-cancer.html.

Akhtari-Zavare M., Juni M.H., Ismail I.Z., Said M.S. and Latiff L.A., 2015. Barriers to breast selfexamination practice among Malaysian female students: a cross-sectional study. Springer Plus 4: 692. https://doi.org/10.1186/s40064-0151491-8.

Bawazir A., Bashateh N., Jadi H. and Breik A.B., 2015. Breast Cancer Screening Awareness and Practices Among Women Attending Primary Health Care Centers in the GhailBawazir District of Yemen. Clin Breast Cancer. 2019 Feb, 19(1):e20-e29. doi: 10.1016/j.clbc.2018.09.005. Epub 2018 Sep 20. PMID: 30497929

Breast health global initiative http://onlinelibrary.wiley .com/doi/10.1002/cncr.v113:8+/issuetoc

Dadzi R. and Adam A., 2018. Assessment of knowledge and practice of breast self examination among reproductive-age women in Akatsi South district of Volta region of Ghana. PLoS One. 2019 Dec 30, 14(12):e0226925. DOI: 10.1371/journal. pone.0226925. PMID: 31887161; PMCID: PMC6936838. Jan 27. doi:10.22034/APJCP. .19 .1 .1556

Dahiya N., Basu S., Singh M.C., Garg S., Kumar R. and Kohli C., 2018. Knowledge and Practices Related to Screening for Breast Cancer among Women in Delhi, India. Asian Pac. J. Cancer Prev., 19(1):155-159.
Dey S., Mishra A., Govil J. and Dhillon P.K., 2015. Breast Cancer Awareness at the Community Level among Women in Delhi, India. Asian Pac. J. Cancer Prev., 16(13):5243-51. doi: 10.7314/ apjcp.2015.16.13.5243. PMID: 26225660.

Fotedar V., Fotedar S., Thakur P., Vats S., Negi A. and Chanderkant L., 2019. Knowledge of breast cancer risk factors and methods for its early detection among the primary health-care workers in Shimla, Himachal Pradesh. J. Educ. Health Promot. Dec 31; 8:265.

HajianTilaki K. and Auladi S., 2015. Awareness, Attitude, and Practice of Breast Cancer Screening Women, and the Associated SocioDemographic Characteristics, in Northern Iran. Iran J. Cancer Prev., 8(4):e3429. doi:10.17795/ ijcp.3429.

Indian Council of Medical Research Department of Health Research - Ministry of Health \& Family Welfare Government of India Media report (2 February to 8 February 2019) (ICMR in News).

Malvia S., Bagadi S.A., Dubey U.S. and Saxena S., 2017. Epidemiology of breast cancer in Indian women. Asia Pac. J. Clinical Oncology Aug; 13(4):289295. DOI: 10.1111/ajco.12661. Epub Feb 9. PMID: 28181405

Moey S.F., Mutalib A.M.A., Mohamed N.C. and Saidin N., 2020. The relationship of socio-demographic characteristics and knowledge of breast cancer on stage of behavioral adoption of breast selfexamination. AIMS Public Health, 7(3):620633. doi:10.3934/publichealth.2020049.

Gondnale N., Ingole A., Mudey A. and Prajapati K., 2019. Perceptions of Women about Breast Cancer in Rural Area of Wardha District. International Journal of Clinical and Biomedical Research, 1: 25-28. 10.31878/ijcbr.2018.51.0

Paul S., Solanki P.P., Shahi U.P. and Srikrishna S., 2015. Epidemiological Study on Breast CancerAssociated Risk Factors and Screening Practices among Women in the Holy City of Varanasi, Uttar Pradesh, India. Asian Pac. J. Cancer Prev.; 16(18):8163-71. doi: 10.7314/apjcp.2015.16.18. 8163. PMID: 26745055.

Sehrawat J.S., Garima and Mor S., 2016. Knowledge, beliefs and practices about breast cancer and its self-examination procedure among urban and rural women of district Gurdaspur, Punjab, 
India: a crosssectional study. International Journal of Community Medicine And Public Health, [S.1.], 4(1):120-128, dec.. ISSN 23946040. Available at: . Date accessed: 30 nov. 2021. doi: https://dx.doi.org/10.18203/23946040.ijcmph20164723.

Siddharth R., Gupta D., Narang R. and Singh P., 2016 Knowledge, attitude and practice about breast cancer and breast self-examination among women seeking outpatient care in a teaching hospital in central India. Indian J. Cancer, 53:226-9.

Singh S., Pal A., Srivastava N.K. and Thakur P., 2008. Level of awareness and practices of women regarding breast cancer in Chhattisgarh, India:
An institution-based survey. Int. J. Med. Public Health, 2018; 8:145-51.

Somdatta P. and Baridalyne N., 2008. Awareness of breast cancer in women of an urban resettlement colony. Indian J. Cancer, 45(4):149-53. doi: 10.4103/0019-509x.44662. PMID: 19112202.

Sung H., Ferlay J., Siegel R.L., Laversanne M., Soerjomataram I., Jemal A. and Bray F., 2021. Global Cancer Statistics 2020: GLOBOCAN Estimates of Incidence and Mortality Worldwide for 36 Cancers in 185 Countries. CA Cancer J. Clin., 71(3):209-249. DOI: 10.3322/caac.21660. Epub 2021 Feb 4. PMID: 335383381.

WHO Breast Cancer, https://www.who.int/healthtopics/cancer. 